\title{
Previsão de Vazão Afluente a um Reservatório Utilizando Previsão Quantitativa de Chuva
}

\author{
Ivanilto Andreolli, Walter Collischonn, Carlos Eduardo Morelli Tucci \\ Instituto de Pesquisas Hidráulicas, IPH/UFRGS \\ ivanilto_andreolli@yahoo.com.br \\ Reinaldo Haas \\ Departamento de Engenharia Sanitária e Ambiental/UFSC \\ haas@ens.ufsc.br \\ José Vicente Miranda Regina \\ Departamento de Planejamento e Controle da Oferta - Tractebel Energia, \\ juicente@tractebelenergia.com.br
}

Recebido: 30/03/04 revisado: 31/10/05 aceito: 31/07/06

\begin{abstract}
RESUMO
A previsão de vazões em tempo real consiste na utilização de modelos hidrológicos para prever a vazão em tempos futuros. Esta previsão pode ser utilizada para alerta hidrológico e para melhorar a operação de sistemas hidrelétricos. Pode ser realizada com base em postos de vazão, com base na precipitação, ou então em ambos. Este artigo apresenta a descrição de uma metodologia de previsão de vazão afluente a reservatórios hidrelétricos baseada na transformação de chuva em vazão utilizando modelo hidrológico distribuído e incorporando previsões quantitativas de precipitação de um modelo meteorológico regional. A metodologia foi aplicada na bacia do rio Uruguai, até o reservatório de Machadinho localizado entre os Estados do Rio Grande do Sul e Santa Catarina. O método proposto foi verificado para três eventos de cheia ocorridos nos anos de 2001 e 2002. Os resultados mostram que a previsão de vazão pode beneficiar-se significativamente da previsão quantitativa de chuva.
\end{abstract}

Palavras-chave: previsão em tempo real, previsão hidrológica, previsão meteorológica, modelos hidrológicos.

\section{INTRODUÇÃO}

O conhecimento antecipado da vazão afluente aos reservatórios de geração de energia elétrica é fundamental para a operação das comportas e para o planejamento da geração de energia nas turbinas deste aproveitamento. Este conhecimento pode trazer benefícios relacionados à segurança da barragem, segurança das populações ribeirinhas, redução de alguns impactos ambientais e maior eficiência na geração de energia (Wood et al., 2002).

Normalmente, as previsões de vazão com antecedência de algumas horas ou dias, como as avaliadas neste trabalho, são denominadas previsões de curto prazo. Elas diferem das previsões de médio prazo (ou sazonais), e das previsões de longo prazo (baseadas em probabilidades, análise de tendências ou cenários de mudanças climáticas).
Existem dois tipos principais de previsões hidrológicas de curto prazo, (Lettenmaier \& Wood, 1993; Tucci, 1998): previsões de propagação em canal e previsões de transformação chuva-vazão. Em alguns casos os modelos de previsão hidrológica podem estar baseados em combinações de modelos de propagação e de transformação chuva-vazão.

A adoção de um ou de outro modelo depende das características do rio e da bacia hidrográfica onde se deseja realizar as previsões. As características mais importantes a serem avaliadas são, (Tucci, 1998): i) $\mathrm{T}_{\mathrm{f}}=$ tempo de antecedência máximo da previsão; ii) $\mathrm{T}_{\mathrm{c}}=$ tempo de resposta das principais sub-bacias (ou tempo de concentração); iii) $\mathrm{T}_{\mathrm{r}}$ = tempo de propagação ao longo do canal principal.

Quando o tempo de antecedência máximo da previsão $\left(\mathrm{T}_{\mathrm{f}}\right)$ é inferior à soma do tempo de concentração e do tempo de propagação, isto é, $\mathrm{T}_{\mathrm{f}}<\mathrm{T}_{\mathrm{c}}$ $+\mathrm{T}_{\mathrm{r}}$, e o tempo de propagação é maior do que o 
tempo de concentração $\left(T_{r} \gg T_{c}\right)$, então as previsões hidrológicas podem ser baseadas em modelos de propagação. Este é o caso de grandes rios, geralmente de baixa declividade, ou com grandes áreas de inundação como o rio Jacuí, (Zamanillo, 1987), ou em sistemas de previsão de antecedência curta, como no caso do rio Doce (Castilho \& Oliveira, 2001).

Quando $T_{f}<T_{c}+T_{r}$, mas $T_{c} \gg T_{r}$, então é necessário um modelo de transformação de chuva em vazão na bacia, ou uma combinação de modelos chuva - vazão e de propagação. Neste caso o modelo chuva - vazão pode ser aplicado utilizando os dados de chuva observada em uma rede de pluviógrafos com transmissão imediata dos dados. Um exemplo que poderia ser colocado nesta categoria é o modelo de previsão proposto por Mine (1998), para o reservatório de Foz do Areia, no rio Iguaçu.

Finalmente, quando $T_{f}>T_{c}+T_{r}$, é necessário utilizar um modelo de transformação de chuva em vazão e aplicá-lo utilizando os dados de chuva observada em uma rede de pluviógrafos com transmissão imediata e, além disso, dados de previsões de chuva, como em Andreolli (2003).

Quando a antecedência das previsões de chuva é desejada para um horizonte de 0 a 3 horas, as melhores previsões são obtidas por radares meteorológicos. Previsões deste tipo são, freqüentemente, denominadas pela palavra em inglês "nowcasting", ou seja, previsão para o instante atual (Smith \& Austin, 2000).

Previsões de chuva com antecedência superior a 3 horas podem ser obtidas operacionalmente utilizando modelos meteorológicos. Os modelos meteorológicos são modelos matemáticos que representam o movimento da mistura ar e vapor de água na atmosfera, e as trocas de calor envolvidas, sujeitos a determinadas condições iniciais e de contorno. Os modelos que representam toda a atmosfera do globo terrestre são denominados modelos globais, e usualmente têm resolução espacial da ordem de centenas de quilômetros, gerando previsões de chuva com antecedências de até uma semana. Normalmente os modelos globais são inadequados para representar as condições das bacias hidrográficas em que se desejam as previsões, especialmente quando o relevo é importante na formação das chuvas. Nestes casos são utilizados modelos regionais, que representam apenas uma parte do globo, porém com maior resolução espacial (4 a 40 $\mathrm{km})$. Os modelos regionais são aplicados utilizando condições de contorno calculadas pelos modelos globais, através da técnica denominada aninhamento ou "downscaling".
A utilização de previsões de chuva de modelos meteorológicos para aplicação em modelos chuva vazão, obtendo previsões de vazão, é recente. Isto ocorre em parte porque havia pouca confiança nas previsões de chuva destes modelos. A chuva é a variável mais difícil de prever em modelos meteorológicos, porém o desenvolvimento de novas metodologias e parametrizações para estes modelos, e o contínuo crescimento da capacidade computacional têm resultado na redução dos erros das previsões de chuva, (Collier \& Krzysztofowicz, 2000; Damrath et al. 2000; Xue et al. 2000 e 2001, Hass, 2002; Hass et al. 2002; Hass et al. 2003; Hollingsworth, 2003; Collischonn et al. 2005). Além disso, os modelos hidrológicos mais simples não têm uma estrutura adequada para tirar proveito das previsões de chuva de alta resolução espacial que são geradas pela nova geração de modelos regionais.

O uso combinado de modelos hidrológicos e modelos meteorológicos para previsões de curto prazo tem sido avaliado experimentalmente e até operacionalmente, com alguns resultados animadores, (Yu et al., 1999; Damrath et al., 2000; Jasper \& Lang, 2002; Koussis et al., 2003).

Este trabalho apresenta uma metodologia de previsão de vazão para o rio Uruguai, até o reservatório de Machadinho, com antecedência de até 48 horas. Como a bacia apresenta um tempo de resposta $\left(T_{c}+T_{r}\right)$ muito curto, bastante inferior a 48 horas, existe a necessidade de utilizar um modelo de transformação chuva-vazão juntamente com previsões de chuva. A metodologia proposta neste trabalho utiliza um modelo de transformação chuva vazão distribuído, especialmente desenvolvido para grandes bacias (Collischonn, 2001), e as previsões de chuva de um modelo regional, aplicado operacionalmente na Universidade Federal de Santa Catarina (Haas et al. 2003). A metodologia proposta foi testada, retroativamente, em 3 eventos isolados ocorridos em 2001 e 2002. Os resultados mostram que há vantagens em utilizar as previsões quantitativas de chuva, especialmente para tempos de antecedência superiores a 12 horas.

\section{METODOLOGIA}

Um modelo hidrológico distribuído por módulos, especialmente desenvolvido para grandes bacias, (Collischonn, 2001) foi aplicado na bacia e calibrado com dados observados. Este modelo foi adaptado para calcular as vazões afluentes ao reservatório de Machadinho em intervalos de tempo de 1 
hora, utilizando precipitação observada ou precipitação prevista pelo modelo meteorológico.

Após a calibração, o modelo foi aplicado para previsão de vazão, com antecedência de até 48 horas, utilizando as previsões de chuva do modelo meteorológico regional.

A figura 1 apresenta um exemplo fictício da previsão de vazão realizada para um instante $\mathrm{T}_{0}+$ T, sendo que ${ }_{\mathrm{T}}$ é a antecedência, variando de 0 até 24 horas. A chuva observada nos postos telemétricos está disponível até o instante $\mathrm{T}_{0}$, e está representada na figura pela parte escura do hietograma. A partir do instante $T_{0}$ a precipitação na bacia não é conhecida. Neste caso a previsão de vazão com modelo chuva-vazão poderá ser realizada de duas formas: i) considerar que a chuva a partir do instante $\mathrm{T}_{0}$ é nula; ii) utilizar a previsão de chuva a partir de $\mathrm{T}_{0}$.

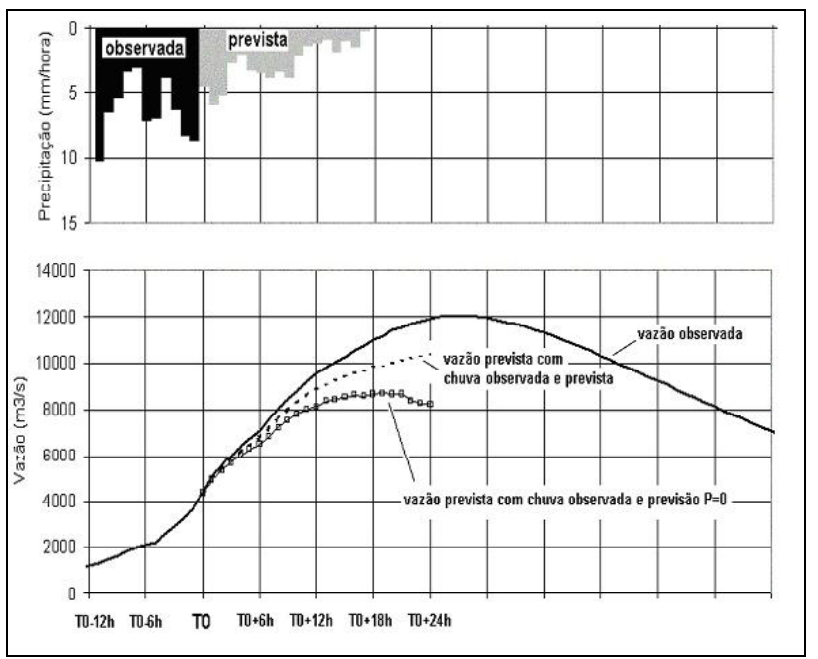

Figura 1 - Resultados hipotéticos de previsão de vazão, a partir de um instante T0, com base na chuva já ocorrida ou com base na chuva já ocorrida e na chuva prevista.

Se a previsão de vazão for realizada com base na hipótese de precipitação nula a partir de $T_{0}$, então existe a tendência de que a vazão prevista seja inferior à vazão observada, como ocorre na figura 1 . Pode-se dizer, inclusive, que o hidrograma previsto com base na hipótese de precipitação nula a partir de $\mathrm{T}_{0}$ representa uma estimativa do limite inferior das vazões futuras. Para antecedências relativamente curtas, entretanto, a previsão de vazão com base na precipitação nula pode ser muito boa, como pode se observar na figura 1, para o caso de antecedência de 6 horas. O tempo de antecedência em que as previ- sões de vazão deste tipo podem ser consideradas de boa qualidade depende fortemente das características da bacia, especialmente do tempo de concentração das sub-bacias, e do tempo de propagação nos rios e reservatórios. Se, por outro lado, existir uma previsão quantitativa de precipitação de boa qualidade para as próximas horas, e esta previsão estiver disponível no instante $\mathrm{T}_{0}$, então a previsão de vazão tende a melhorar, como mostra a figura 1 .

\section{A BACIA DO RIO URUGUAI ATÉ MACHADINHO}

A área da bacia do rio Uruguai considerada neste estudo envolve as sub-bacias 70, 71 e parte da 72 (numeração da ANEEL), cobrindo uma área total de, aproximadamente, $32.000 \mathrm{~km}^{2}$, até a barragem de Machadinho (figura 2).

As nascentes dos rios Canoas e Pelotas (dois dos principais rios da região) estão localizadas em uma região de campos e florestas, a uma altitude que ultrapassa os $1.500 \mathrm{~m}$. O relevo da bacia é bastante pronunciado e os rios, especialmente o rio Pelotas, apresentam grande declividade. Atualmente, a confluência dos rios Pelotas e Canoas, que marca o início do rio Uruguai, está na região de remanso do reservatório de Machadinho.

A bacia do rio Uruguai, a montante de Machadinho, está inteiramente localizada na região do derrame basáltico sul-brasileiro. Em geral, as rochas que formam o substrato desta região apresentam pouca porosidade e baixa capacidade de absorver e armazenar a água do solo. Os solos na bacia do rio Uruguai a montante de Machadinho contêm altos teores de argila, o que contribui para reduzir a capacidade de infiltração. Além disso, a camada de solo sobre o substrato rochoso nas regiões das encostas é relativamente fina, apresentando pouca capacidade de armazenamento. Assim, as características de geologia e solos da região contribuem para uma baixa capacidade de regularização natural de vazão na bacia, com grande predomínio do escoamento superficial em detrimento do escoamento subterrâneo.

Além do basalto, que predomina de maneira geral na bacia, existem regiões em que ocorre o afloramento de rochas sedimentares de arenito, especialmente na bacia do rio Canoas, o que condiciona alguns aspectos da hidrologia da região e dá origem a diferenças de comportamento entre os dois principais rios da região: Pelotas e o Canoas. 
A vegetação original na bacia era de florestas, com exceção das regiões mais altas, em que existem alguns campos nativos. Grande parte das florestas foi substituída por lavouras ou pastagens a partir do início do século XX.

Em conseqüência das características físicas da bacia, tais como relevo pronunciado, fortes declividades, solos relativamente argilosos, rasos e pouco permeáveis e substrato rochoso de basalto com baixa capacidade de armazenamento e regularização, as cheias no rio Uruguai ocorrem com muita rapidez e a vazão do rio é altamente variável.

A bacia do rio Uruguai a montante dos reservatórios de Machadinho e Itá conta com uma boa rede de monitoramento hidrológico, especialmente por instrumentos com sistema de aquisição e transmissão de dados por telemetria (pluviógrafos e linígrafos). Esta rede telemétrica iniciou sua operação em maio de 2001 e foi sendo incrementada com novos postos entrando em operação até setembro de 2001. Atualmente existem 16 pluviógrafos e 36 pluviômetros (instrumentos manuais de leitura de chuva) em operação na bacia. Os dados dos pluviômetros são obtidos manualmente duas vezes ao dia e foram importantes para calibração do modelo hidrológico. Os dados da rede telemétrica são armazenados e transmitidos em intervalos de 1 hora, o que é adequado para representar as rápidas variações de nível dos rios da região. Os linígrafos estão localizados no rio canoas (Passo Caru) e rio Pelotas (Passo Socorro). Em Machadinho, os registros de níveis são obtidos a cada 4 horas. A figura 2 apresenta a distribuição dos postos de chuva e a localização dos linígrafos.

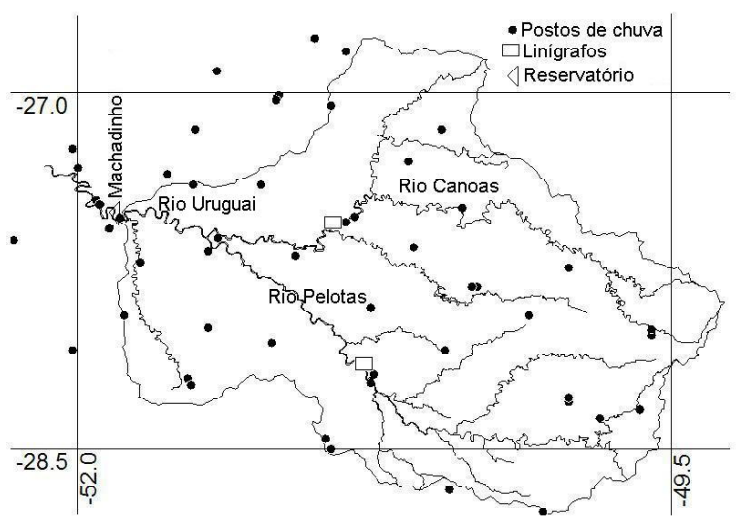

Figura 2 - Rede de postos de chuva e linígrafos na bacia do rio Uruguai até Machadinho.

\section{O MODELO HIDROLÓGICO}

Collischonn (2001) desenvolveu um modelo hidrológico distribuído, especialmente para ser aplicado em grandes bacias. Este modelo utiliza informações de imagens de satélite, modelos numéricos de terreno e mapas digitais do uso do solo, vegetação, relevo e tipos de solo. No modelo a bacia é dividida em células quadradas, cada qual é subdividida em blocos representando o tipo de solo, uso do solo e vegetação.

$\mathrm{O}$ intervalo de tempo utilizado pelo modelo é flexível, podendo ser ajustado às necessidades do intervalo de previsão, de simulação e dos dados disponíveis. O balanço de água é computado de forma independente em cada bloco e em cada célula do modelo. Os valores de chuva são interpolados espacialmente em cada intervalo de tempo para estimar a chuva em cada célula do modelo, usando a função inverso do quadrado da distância.

O modelo tem componentes representando a interceptação, evaporação, infiltração, escoamento superficial, sub-superficial e subterrâneo e de reservatórios virtuais de armazenamento. $\mathrm{O}$ escoamento gerado em cada célula do modelo é propagado até a rede de drenagem utilizando 3 reservatórios lineares (superficial, sub-superficial e subterrâneo). A vazão é propagada através da rede de drenagem do rio usando o método Muskingum-Cunge.

Nesse estudo a bacia do rio Uruguai foi discretizada em células de $0,1 \times 0,1$ graus, o que corresponde a, aproximadamente, $10 \times 10 \mathrm{~km}$ nesta região.

Para facilitar a calibração, a bacia também foi dividida em sub-bacias, de acordo com a disponibilidade de dados para a calibração. A figura 3 apresenta a bacia discretizada e subdividida em 5 bacias (Rio Canoas, Rio Pelotas, Rio Inhandava, Incremental do rio Canoas, Incremental do Pelotas até Machadinho).

O modelo foi calibrado utilizando os dados disponíveis de precipitação e vazão, fornecidos pelo CLIMERH- SC através da Tractebel Energia S.A. O período completo corresponde aos dados de maio de 2001 a maio de 2003. Entretanto, entre maio e setembro de 2001 há poucos dados de pluviógrafos, e os dados de abril e maio de 2003 foram utilizados apenas para verificação. Assim, o período utilizado para a calibração se estende de setembro de 2001 a março de 2003.

Uma grande cheia ocorreu logo no início deste período. No dia $01 / 10 / 2001$ a vazão no rio Pelotas no posto Passo do Socorro atingiu $5.312 \mathrm{~m}^{3} \mathrm{~s}^{-1}$ 
(de acordo com a cota medida pelo linígrafo, às 11:00 do dia 01/10/2001). Na medição manual na régua a vazão do dia 01/10/2001 foi de $5.119 \mathrm{~m}^{3} \mathrm{~s}^{-1}$. No rio Canoas, em Passo Caru, o linígrafo apresentou problemas e a vazão máxima de $2.578 \mathrm{~m}^{3} \mathrm{~s}^{-1}$ foi registrada por leitura da régua no dia 02/10/2001. No reservatório de Machadinho a vazão afluente, estimada por balanço hídrico, atingiu $13.787 \mathrm{~m}^{3} \mathrm{~s}^{-1}$.

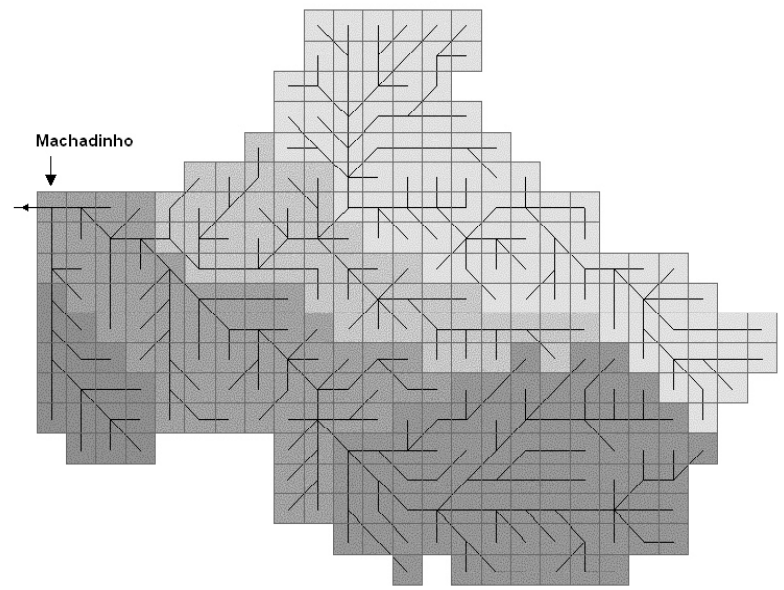

Figura 3 - Discretização do modelo hidrológico, dividindo a bacia em 291 células interligadas pela rede de drenagem.

A precipitação total neste evento atingiu 200 mm em 24 horas em alguns postos pluviográficos do sul da bacia. Na bacia do rio Pelotas a precipitação média, estimada por interpolação dos dados no modelo distribuído, foi de $150 \mathrm{~mm}$, aproximadamente, durante este evento.

Após esta grande cheia, ocorreu um período de poucas chuvas, especialmente entre dezembro de 2001 e abril de 2002, mas o período entre julho de 2002 e março de 2003 apresentou mais alguns eventos de cheias, embora nenhum deles tenha magnitude comparável ao de setembro e outubro de 2001.

Para obter uma melhor calibração do modelo hidrológico, foram utilizados dados de pluviômetros e pluviógrafos em toda a bacia. Os dados dos pluviômetros, em intervalo de tempo diário, foram distribuídos no tempo em intervalo horário, de acordo com a distribuição temporal do posto pluviográfico mais próximo, (Tucci et al., 2003). Esta metodologia foi adotada para enriquecer os dados de chuva com o máximo de informação disponível, com o objetivo de reduzir os desvios e tendências embutidos no processo de calibração.

Para a calibração partiu-se de valores de parâmetros encontrados durante simulações anterio- res da bacia do rio Uruguai, (Collischonn et al., 2003; Tucci et al., 2003). A partir desta estimativa inicial os parâmetros foram alterados buscando um bom ajuste entre hidrogramas observados e calculados em Machadinho e em dois linígrafos localizados a montante de Machadinho: o posto Passo Caru, no rio Canoas, e o posto Passo do Socorro, no rio Pelotas.

A calibração foi realizada utilizando a metodologia automática multi-objetivo MOCOM-UA (Yapo \& Sorooshian, 1998). As funções objetivo consideradas foram os valores do coeficiente de eficiência NS, da vazão nos postos Passo Caru e Passo do Socorro e da vazão afluente ao reservatório de Machadinho, de acordo com a equação (1).

$\mathrm{NS}=1-\frac{\sum\left(\mathrm{Q}_{\mathrm{obs}}(\mathrm{t})-\mathrm{Q}_{\mathrm{cal}}(\mathrm{t})\right)^{2}}{\sum\left(\mathrm{Q}_{\mathrm{obs}}(\mathrm{t})-\overline{\mathrm{Q}_{\mathrm{obs}}}\right)^{2}}$

Na equação (1) NS é o coeficiente de NashSutcliffe; $Q_{\text {obs }}(t)$ é a vazão observada no tempo $t$, $\mathrm{Q}_{\text {cal }}(\mathrm{t})$ é a vazão calculada no tempo $\mathrm{t}$ e $\overline{\mathrm{Q}_{\mathrm{obs}}}$ é a média das vazões observadas.

Os resultados da calibração foram avaliados através da análise visual do ajuste entre hidrogramas calculados e observados e pelos valores das funções objetivo. A tabela 1 apresenta o coeficiente NS obtido em Machadinho e nos postos Passo Caru e Passo do Socorro, e o erro de volume $(\Delta \mathrm{V})$ calculado, durante todo o período de calibração (set. 2001 a mar. 2003). A figura 4 apresenta a parte do hidrograma correspondente ao inverno de 2002.

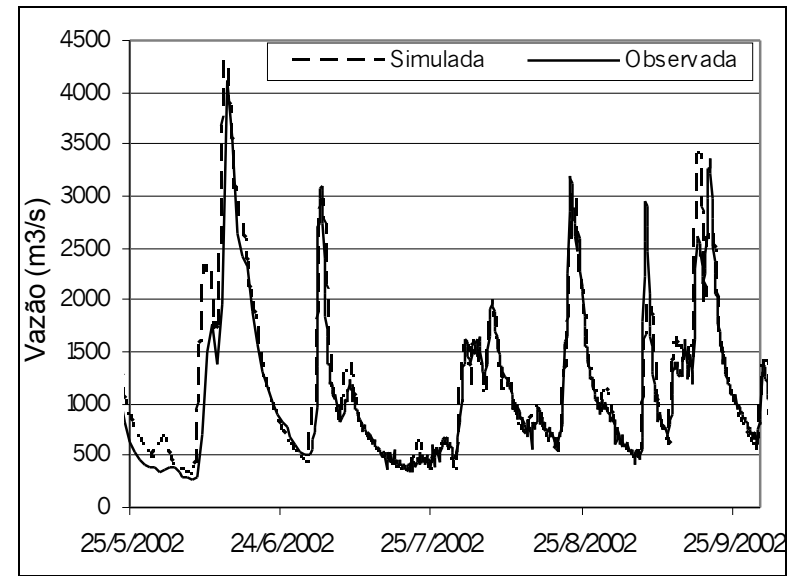

Figura 4 - Resultados de vazão calculada no rio Uruguai em Machadinho após a calibração (mai/2002 a set/2002). 
A previsão de vazão em tempo real pode ser incrementada pelo contínuo monitoramento da qualidade dos resultados e pela atualização de variáveis do modelo de previsão. A correção dessas variáveis e o acompanhamento dos resultados é importante devido às incertezas envolvidas na estimativa e nas medições das mesmas. As incertezas envolvem a variabilidade espacial e temporal das variáveis e erros de medições. Esta atualização pode incluir correção de valores de variáveis como o armazenamento em rios e reservatórios, e em reservatórios (virtuais) do modelo matemático, como o que representa a umidade do solo (Refsgaard, 1997).

Tabela1 - Resultados das funções objetivo na calibração

\begin{tabular}{|c|l|l|l|}
\hline Função & $\begin{array}{l}\text { Passo do } \\
\text { Socorro }\end{array}$ & Passo Caru & Machadinho \\
\hline NS & 0,81 & 0,85 & 0,89 \\
\hline V [\%] & 9,4 & 8,3 & 3,2 \\
\hline
\end{tabular}

Técnicas de atualização mais simples podem ser necessárias em modelos de previsão distribuídos quando o objetivo dessas previsões é operacional. Uma técnica simples, baseada na correção em tempo real dos reservatórios virtuais e das vazões em cada célula do modelo foi desenvolvida, (Tucci et al, 2003) e adaptada para este estudo. A técnica de atualização adaptada está baseada na utilização de dados medidos nos rios Canoas e Pelotas (disponíveis em tempo real nos postos telemétricos) e das vazões afluentes ao reservatório de Machadinho. Os valores de vazão calculados pelo modelo, com antecedência de zero horas, são comparados com os valores de vazão observada em cada um dos postos, gerando um fator de correção de atualização (FCA) conforme a equação (2):

$\mathrm{FCA}=\mathrm{Q}_{\mathrm{obs}} / \mathrm{Q}_{\text {calc }}$

onde FCA é o fator de correção; $Q_{\text {obs }}$ é a vazão observada e $Q_{\text {calc }}$ é a vazão calculada.

A seguir, a vazão dos rios, em todas as células a montante da célula correspondente ao posto fluviométrico, é corrigida por este mesmo fator de correção, utilizando a equação (3):

$\mathrm{Q}_{\text {atual }}=\mathrm{FCA} \cdot \mathrm{Q}_{\text {calc }} \cdot\left(\mathrm{A}_{\mathrm{i}} / \mathrm{A}_{\mathrm{p}}\right)+\mathrm{Q}_{\text {calc }} \cdot\left[1-\left(\mathrm{A}_{\mathrm{i}} / \mathrm{A}_{\mathrm{p}}\right)\right]$

onde $Q_{\text {atual }}$ é a vazão atualizada; $A_{\mathrm{i}}$ é a área a montante da célula considerada; e $\mathrm{A}_{\mathrm{P}}$ é a área de drenagem no posto fluviométrico onde é observada a vazão $Q_{\text {obs }}$.
Durante as estiagens também é realizada a atualização dos volumes armazenados nos reservatórios que representam os aqüíferos (reservatório subterrâneo de cada célula). Esta atualização está baseada no mesmo fator de correção, e é aplicada considerando um ponderador, conforme a equação (4).

$\mathrm{VB}_{\mathrm{a}}=\mathrm{FCA} \cdot \mathrm{VB}_{\mathrm{C}} \cdot\left(\mathrm{PB}_{\mathrm{i}}\right)+\mathrm{VB}_{\mathrm{C}} \cdot\left(1-\mathrm{PB}_{\mathrm{i}}\right)$

Nesta equação $\mathrm{VB}_{\mathrm{a}}$ é o volume no reservatório subterrâneo atualizado; $\mathrm{VB}_{\mathrm{c}}$.é o volume calculado; e PBi é a parcela da vazão na célula i que é oriunda do escoamento subterrâneo. Esta última variável é calculada continuamente pelo modelo hidrológico, conforme descrito em, Collischonn (2001).

Utilizando esta técnica de atualização foi possível melhorar as previsões, porque as condições em que o modelo inicia a previsão estão sempre próximas das condições reais, observadas nos postos. Entretanto, a atualização não impede a perda de qualidade da previsão em antecedências maiores. Isto ocorre porque a influência das variáveis atualizadas diminui à medida em que aumenta a antecedência da previsão.

\section{DADOS DE PREVISÃO METEOROLÓGICA}

As previsões de chuva utilizadas neste trabalho são frutos de um projeto de pesquisa paralelo, desenvolvido pela UFSC, (Haas et al., 2003). Estas previsões correspondem à variável precipitação na superfície calculada pelo modelo meteorológico ARPS (Advanced Regional Prediction System - (Xue et al., 2000; Xue et al., 2001)).

O ARPS é um modelo tri-dimensional, não hidrostático destinado para representar explicitamente eventos convectivos e previsões de tempo em diversas escalas. Diversas variáveis podem ser previstas pelo modelo ARPS como: neve, componentes cartesianas de vento e chuvas. Fenômenos meteorológicos que ocorrem em escalas que vão de poucos metros a centenas de quilômetros podem ser previstos pelo modelo. O modelo ARPS é bastante flexível permitindo a utilização de várias opções de parametrização e de micro-física (Xue et al., 2000).

Neste estudo o ARPS foi configurado com três aninhamentos sucessivos: 40, 12 e 4 km de resolução horizontal, conforme figura 5 . As condições inicial e de fronteira foram assimiladas do modelo global GFS (Global Forecasting System) do NCEP (National Environmental Prediction Center,) com 
grade de $1^{\circ}$ de resolução horizontal. As saídas do GFS foram aninhadas na grade de $40 \mathrm{~km}$. Utilizando-se a técnica de aninhamento de uma via, a grade de $12 \mathrm{~km}$ foi aninhada na grade de $40 \mathrm{~km}$ e a grade de $4 \mathrm{~km}$ aninhada na grade de $12 \mathrm{~km}$.

Nas três grades foram utilizados 35 níveis verticais com espaçamento variável segundo uma função hiperbólica. O espaçamento variou de 20 metros na superfície até 600 metros na metade da altura atmosférica representada. $\mathrm{O}$ modelo foi integrado por 60 horas na grade de $40 \mathrm{~km}$, por 50 horas na grade de $12 \mathrm{~km}$ e 36 horas na grade de $4 \mathrm{~km}$. A freqüência de atualização das fronteiras ocorre a cada 6 horas na grade de $40 \mathrm{~km}$ e a cada hora nas grades internas.

A assimilação de dados foi feita com o uso do ADAS (Data Assimilation System - (Brewster, 1996)). Os dados de METAR, SYNOP e imagens de satélite IR e VIS no formato MciDAS, foram assimilados na grade de $40 \mathrm{~km}$, com o uso do método de correções sucessivas de Bratseth, (Bratseth, 1986) contra o campo de fundo (First Guess) proveniente do GFS.

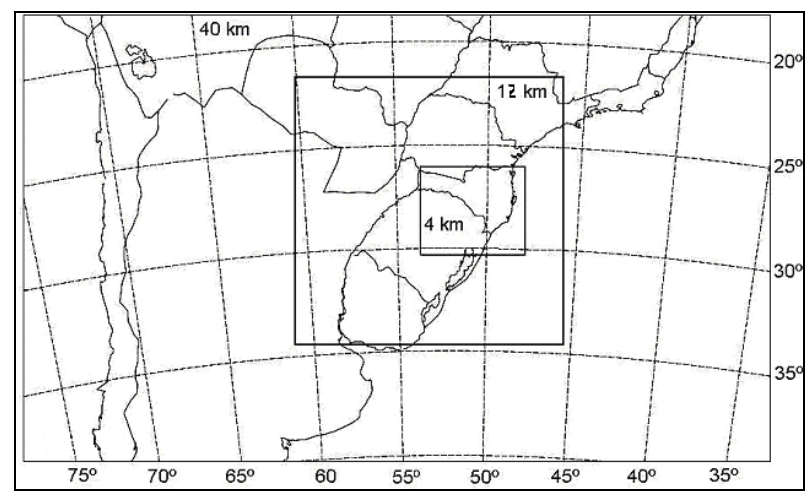

Figura 5 - Abrangência espacial do modelo meteorológico regional, para as três discretizações: $4 \mathrm{~km}, 12 \mathrm{~km}$ e $40 \mathrm{~km}$.

Para todas as grades foi usada a parametrização da convecção de Kain e Fritsch (Kain e Fritsch, 1993), a parametrização de microfísica de gelo baseado de Lin-Tao (Lin et al., 1983; Tao e Simpson, 1993), a parametrização de turbulência na subgrade de Sun e Chang (Sun e Chang, 1985) e a parametrização de radiação de ondas longas e curtas proposta por Chou (Chou et al., 1990 e 1992).

O modelo foi rodado em modo paralelo com passos de tempos grande "dtbig" e pequeno "dtsml”, apropriados a cada grade. Foi utilizado um filtro computacional e filtro Asselin adequados para controlar as ondas instáveis de baixa freqüência. Na vertical foi utilizada a opção implícita que é estável para a propagação de ondas de som. Nas opções numéricas dos termos de advecção, foi utilizado um esquema "leapfrog" de quarta ordem na horizontal e de segunda ordem nos termos na vertical. Nos demais termos foram utilizados um esquema "leapfrog" de segunda ordem.

O modelo de solo e vegetação utilizado é baseado em Noilhan e Planton (1989). O calculo do fluxo de calor latente e sensível do solo é feito com base em coeficientes calculados pelo modelo, baseados na teoria de similaridade. Os fluxos na superfície são suavizados com um filtro retangular de 5 pontos, de modo a evitar o crescimento de ondas espúrias. O cálculo do fluxo de calor, umidade e atrito sobre os oceanos são baseados em Anderson (1993). Usou-se também a opção de redistribuição da umidade nos primeiros 200 metros, baseada na teoria de similaridade.

As previsões do modelo ARPS são realizadas rotineiramente duas vezes ao dia, uma correspondendo ao horário 00:00 Z (horário de Greenwich) e outra no horário 12:00 Z, o que corresponde às 21:00 e 09:00 no horário local. A realização das previsões meteorológicas com o modelo ARPS depende de um fluxo de informações que se inicia pela obtenção dos dados de previsão do modelo global. A partir daí é executado o modelo ARPS em resolução de $40 \mathrm{~km}$, em uma área que cobre boa parte do sul da América do Sul, desde o sul do estado de Goiás, ao Norte, até Bahia Blanca, ao Sul, e em uma extensão Leste - Oeste de $4.000 \mathrm{~km}$ desde o Oceano Pacífico, a Oeste, até o Oceano Atlântico a cerca de $1.500 \mathrm{~km}$ da costa do Sul do Brasil, a Leste.

O modelo ARPS de resolução de $40 \mathrm{~km}$ é executado por um período de 60 horas, e seus resultados fornecem as condições de contorno para o modelo ARPS de $12 \mathrm{~km}$ de resolução, cuja abrangência espacial é menor, cobrindo os três estados do Sul do Brasil, o Uruguai, parte da Argentina e do Paraguai, e parte dos estados de São Paulo e Mato Grosso do Sul. O modelo ARPS de $4 \mathrm{~km}$ de resolução recebe as condições de contorno do modelo de $12 \mathrm{~km}$ e sua abrangência limita-se ao Estado de Santa Catarina e o norte do Rio Grande do Sul. Portanto, a seqüência de previsão consiste de: i) obtenção de dados do modelo global; ii) execução do modelo ARPS 40; iii) execução do modelo ARPS 12; iv) execução do modelo ARPS 4.

Neste estudo arquivos digitais com previsões quantitativas de precipitação foram disponibilizados pela equipe da UFSC para eventos isolados de cheias, de 30/09 a 02/10 de 2001; de 09/11 a 11/11 de 
2002; e de $25 / 11$ a 30/11 de 2002 e para o período contínuo de 04/2003 a 10/2003.

\section{RESULTADOS}

O maior evento analisado neste trabalho ocorreu entre os meses de setembro e outubro de 2001, quando estava sendo finalizado o primeiro enchimento do reservatório de Machadinho. A precipitação ocorreu nos dias 30/09 e 01/10, com maior intensidade no período das 06:00 do dia 30/09 até as 11:00 do dia 01/10, e atingiu pouco menos de $200 \mathrm{~mm}$ nos postos de Vacaria, Lagoa Vermelha e Lages, que ficam na região sul da bacia. Na região norte da bacia a precipitação foi menos intensa, atingindo $130 \mathrm{~mm}$ no posto Passo Caru, e pouco mais de $60 \mathrm{~mm}$ em Campos Novos. Esta precipitação resultou em uma grande cheia, originada especialmente na sub-bacia do rio Pelotas, que atingiu a vazão máxima instantânea de $5.000 \mathrm{~m}^{3} \mathrm{~s}^{-1}$ no posto Passo do Socorro. De acordo com as estimativas por balanço hídrico, a vazão máxima diária afluente ao reservatório de Machadinho foi de, aproximadamente, $14.000 \mathrm{~m}^{3} \mathrm{~s}^{-1}$.

As previsões de chuva disponibilizadas para este evento foram: i) Previsão com o modelo ARPS de resolução $40 \mathrm{~km}$; aplicado com as condições iniciais correspondentes às 21:00 do dia 29/set, com resultados para o período de 60 horas estendendose das 21:00 do dia 29/set até às 09:00 do dia 02/out. ii) Previsão com o modelo ARPS de resolução $12 \mathrm{~km}$; aplicado com as condições iniciais correspondentes às 21:00 do dia 29/set, com resultados para o período de 50 horas estendendo-se das 07:00 do dia 30/set até às 09:00 do dia 02/out. iii) Previsão com o modelo ARPS de resolução $4 \mathrm{~km}$; aplicado com as condições iniciais correspondentes às 21:00 do dia 29/set, com resultados para o período de 26 horas estendendo-se das 07:00 do dia 30/set até às 09:00 do dia 01/out.

Em todas as previsões os dados de chuva observada nos pluviômetros e pluviógrafos foram utilizados até o instante $\mathrm{T}_{0}$. A partir deste instante foram utilizadas as chuvas previstas pelo modelo meteorológico nas suas diferentes resoluções. Para comparação foram realizadas, também, previsões considerando que a precipitação a partir do instante $\mathrm{T}_{0}$ é nula. É importante observar, também, que todas as previsões de vazão realizadas incorporaram a metodologia de atualização do modelo hidrológico.

As figuras 6 a 10 mostram os resultados da previsão de vazão, juntamente com a vazão observada.

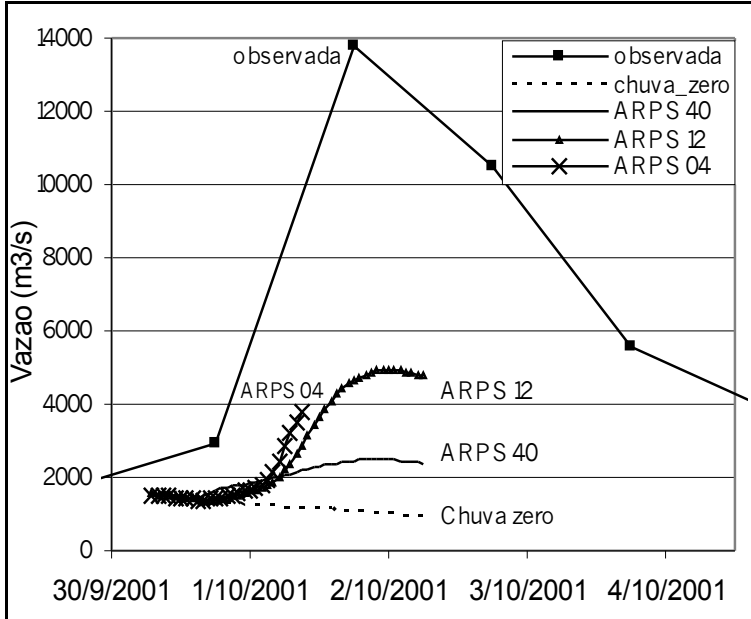

Figura 6 - Previsões realizadas para o evento de set/out de 2001, iniciadas no dia 30/set às 07:00 horas.

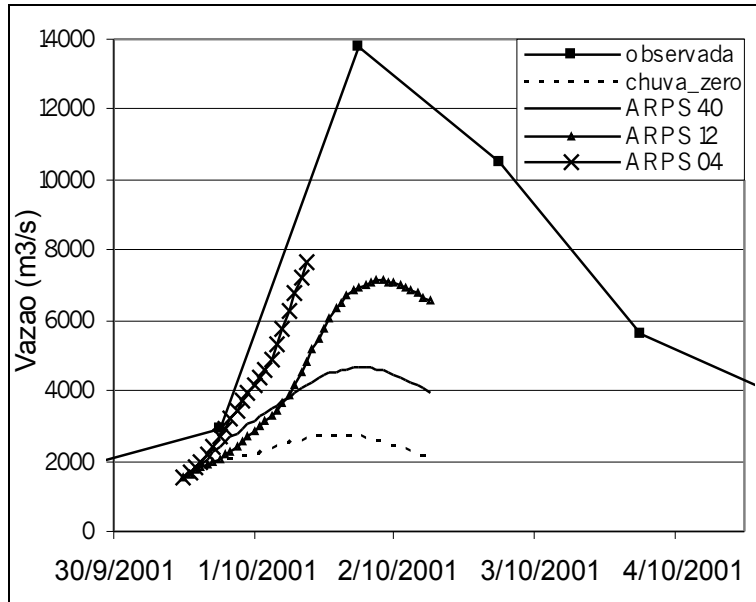

Figura 7 - Previsões realizadas para o evento de set/out de 2001, iniciadas no dia 30 /set às 12:00 horas.

A figura 6 apresenta a previsão de vazão realizada no instante $\mathrm{T}_{0}=07: 00$ horas do dia 30/set. Neste instante a vazão afluente ao reservatório de Machadinho é de, aproximadamente, $2.000 \mathrm{~m}^{3} \mathrm{~s}^{-1}$, e a precipitação acumulada na bacia ainda é pequena, atingindo no máximo $20 \mathrm{~mm}$ em Vacaria. Em conseqüência disso, a previsão de vazão considerando chuva nula a partir de $\mathrm{T}_{0}=07: 00$ horas indica uma redução da vazão nas próximas 24 a 48 horas. Por outro lado, as previsões de vazão baseadas na previ- 
são de chuva do modelo ARPS de $40 \mathrm{~km}$ indicam que a chuva poderá aumentar a vazão afluente, e as previsões com o modelo ARPS de $12 \mathrm{~km}$ indicam que a vazão afluente poderá chegar a $5.000 \mathrm{~m}^{3} \mathrm{~s}^{-1} \mathrm{em}$ cerca de 36 horas. O horizonte das previsões com o modelo ARPS de $4 \mathrm{~km}$ não permite avançar a previsão de vazão além da manhã do dia 01/out, mas indicam um crescimento do hidrograma ainda mais rápido do que o previsto com base no modelo ARPS de $12 \mathrm{~km}$.

A figura 7 mostra as previsões realizadas no instante $\mathrm{T}_{0}=12: 00$ horas do dia $30 /$ set, quando a precipitação acumulada no sul da bacia já chega a $70 \mathrm{~mm}$, desde o início do evento. Mesmo assim, a vazão afluente ao reservatório, neste momento, ainda é inferior a $3.000 \mathrm{~m}^{3} \mathrm{~s}^{-1}$, de acordo com os dados observados. Neste momento, utilizando as mesmas previsões de chuva (rodada dos modelos iniciada às 21:00 horas do dia 29/set, em horário local), as previsões de vazão já indicam um crescimento maior do hidrograma nas próximas 12 a 36 horas. As previsões baseadas no modelo ARPS de $40 \mathrm{~km}$ indicam um pico de mais de $4.000 \mathrm{~m}^{3} \mathrm{~s}^{-1}$, as do modelo ARPS de $12 \mathrm{~km}$ indicam um pico de $7.000 \mathrm{~m}^{3} \mathrm{~s}^{-1} \mathrm{e}$ as baseadas no modelo ARPS de $4 \mathrm{~km}$ indicam um crescimento até $8.000 \mathrm{~m}^{3} \mathrm{~s}^{-1}$ ainda antes de atingir o pico.

Embora a chuva observada até este momento $\left(\mathrm{T}_{0}=12: 00\right.$ horas do dia $\left.30 / \mathrm{set}\right)$ seja significativa em alguns locais, ela ainda é muito concentrada no sul da bacia. Em conseqüência disso, a vazão prevista com chuva nula a partir de $\mathrm{T}_{0}$ mostra um crescimento pequeno, não chegando a atingir $3000 \mathrm{~m}^{3} \mathrm{~s}^{-1}$ (figura 7).

A figura 8 mostra as previsões de vazão realizadas no instante $\mathrm{T}_{0}=18: 00$ horas do dia 30/set, quando a precipitação acumulada na bacia já supera $100 \mathrm{~mm}$ em alguns locais, e já atinge também a bacia do rio Canoas. Neste momento, a previsão com base na precipitação nula a partir do tempo $\mathrm{T}_{0}$ indica que o pico da cheia será de $8.000 \mathrm{~m}^{3} \mathrm{~s}^{-1}$. Este resultado é muito importante, porque esta previsão foi feita com cerca de 24 horas de antecedência, e porque representa uma estimativa do limite mínimo que o pico pode atingir. As previsões de vazão baseadas na previsão de precipitação do modelo ARPS, neste mesmo momento, mostram que o crescimento do hidrograma será mais rápido do que o previsto considerando chuva nula, e o pico será superior a $8.000 \mathrm{~m}^{3} \mathrm{~s}^{-1}$, devendo atingir $12.000 \mathrm{~m}^{3} \mathrm{~s}^{-1}$, em cerca de 24 horas.

O que se observa nestas figuras é que a inclusão de novos dados observados no sistema de previsão permite melhorar a previsão de vazão à medida que avança o tempo, mesmo que os dados de previsão de precipitação utilizados sejam sempre os mesmos, como mostram as figuras 6 até 10. A figura 9, por exemplo, mostra que considerando o instante $\mathrm{T} 0=24: 00$ horas do dia 30 set, a previsão de vazão indica picos entre $11.000 \mathrm{~m}^{3} \mathrm{~s}^{-1}$ com chuva zero e $15.000 \mathrm{~m}^{3} \mathrm{~s}^{-1}$ com previsão pelo ARPS 12 .

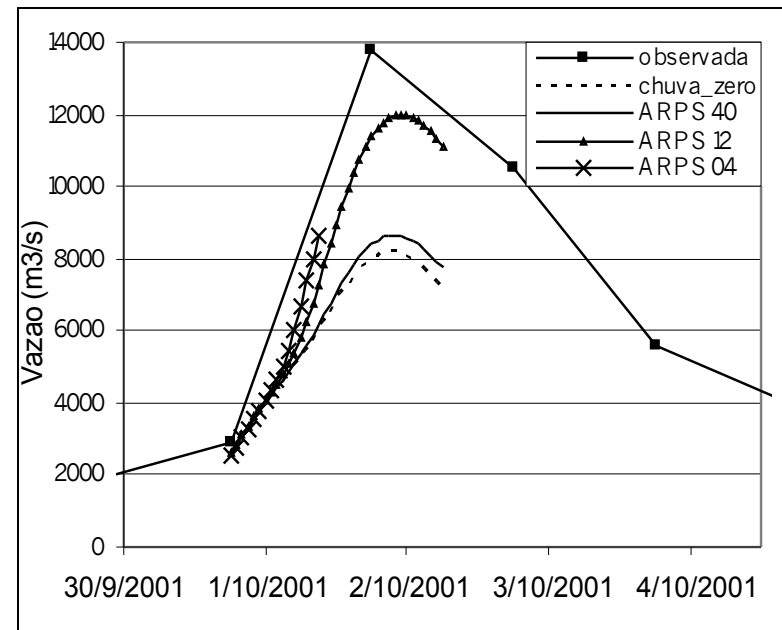

Figura 8 - Previsões realizadas para o evento de set/out de 2001, iniciadas no dia 30 /set às 18:00 horas.

Finalmente, na previsão iniciada no tempo T0=06:00 do dia 01/out (figura 10), todas as previsões realizadas indicam que o pico da vazão será de, aproximadamente, $14.000 \mathrm{~m}^{3} \mathrm{~s}^{-1}$, como de fato ocorreu.

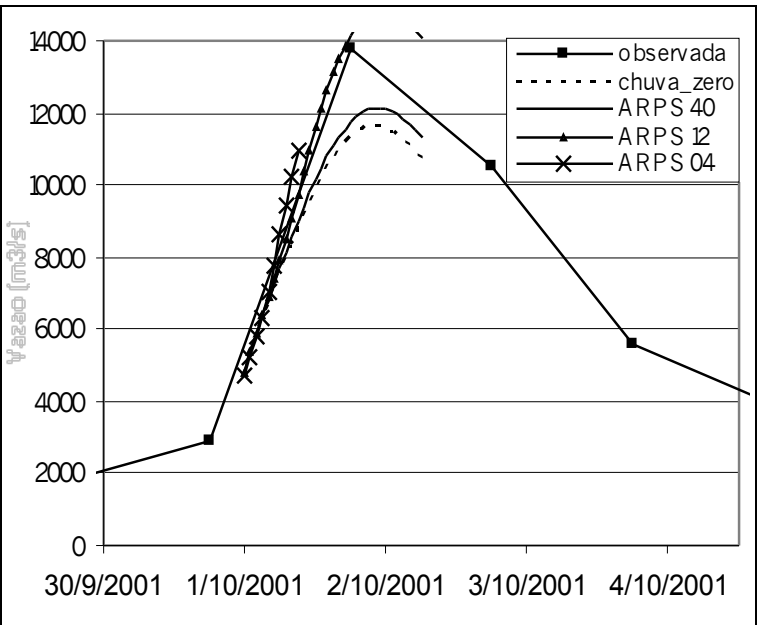

Figura 9 - Previsões realizadas para o evento de set/out de 2001, iniciadas no dia 30 /set às 24:00 horas.

Portanto, no caso do evento de 30 de set. e 01 de out. de 2001, quando a vazão afluente ao re- 
servatório de Machadinho atingiu cerca de 14.000 $\mathrm{m}^{3} \mathrm{~s}^{-1}$, as previsões de vazão com base na previsão de chuva indicaram um aumento significativo das vazões, com antecedência de mais de 24 horas, entretanto subestimaram a magnitude do pico. Para tempos de antecedência entre 12 e 24 horas, entretanto, a vazão de pico prevista indicou valores mais próximos aos observados. Finalmente, para 12 horas de antecedência, todos os tipos de previsão indicaram a vazão de pico próxima a $14.000 \mathrm{~m}^{3} \mathrm{~s}^{-1}$, como o valor observado.

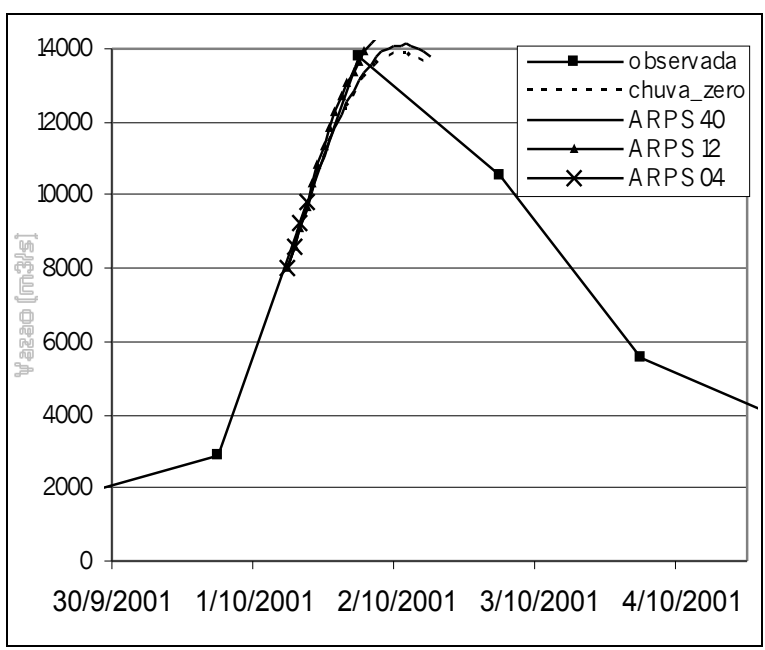

Figura 10 - Previsões realizadas para o evento de set/out de 2001, iniciadas no dia 01/out às 06:00 horas.

Com relação às diferentes versões do modelo ARPS, com resolução espacial de $40 \mathrm{~km}, 12 \mathrm{~km}$ e $4 \mathrm{~km}$, esperava-se uma redução do erro da previsão de chuva com o aumento da resolução espacial. Em outras palavras, o modelo ARPS de $4 \mathrm{~km}$ deveria resultar em previsões melhores do que as do modelo ARPS de $12 \mathrm{~km}$ e este em previsões melhores do que as do modelo ARPS de $40 \mathrm{~km}$. No evento de setembro e outubro de 2001, analisado aqui, isto ocorreu, de fato. As previsões de vazão baseadas nas previsões do modelo ARPS de $12 \mathrm{~km}$ de resolução foram mais corretas do que as do modelo ARPS de $40 \mathrm{~km}$. As previsões do modelo ARPS de $4 \mathrm{~km}$ de resolução, embora com um horizonte mais curto, resultaram em previsões mais corretas da subida do hidrograma do que as previsões do modelo ARPS $12 \mathrm{~km}$.

O segundo evento analisado corresponde ao período de 9 a 12 de novembro de 2002, quando a vazão máxima afluente ao reservatório de Machadinho foi estimada em, aproximadamente, 3.000 $\mathrm{m}^{3} \mathrm{~s}^{-1}$. A figura 11 mostra que a simulação de vazão neste evento, utilizando o modelo hidrológico com a chuva observada nos pluviômetros e pluviógrafos, se ajusta bem ao hidrograma observado.

As previsões de chuva disponibilizadas para este evento foram: i) Previsão com o modelo ARPS de resolução $40 \mathrm{~km}$; aplicado com as condições iniciais correspondentes às 09:00 do dia 09/nov/2002, com resultados para o período de 60 horas estendendo-se das 09:00 do dia 09/nov/2002 até às 21:00 do dia 12/nov/2002. ii) Previsão com o modelo ARPS de resolução $12 \mathrm{~km}$; aplicado com as condições iniciais correspondentes às 09:00 do dia 09/nov/2002, com resultados para o período de 50 horas estendendo-se das 19:00 do dia 09/nov/2002 até às 21:00 do dia 12/nov/2002.

Como no evento de 2001, em todas as previsões os dados de chuva observada nos pluviômetros e pluviógrafos foram utilizados até o instante $\mathrm{T}_{0}$ e a partir deste instante foram utilizadas as chuvas previstas.

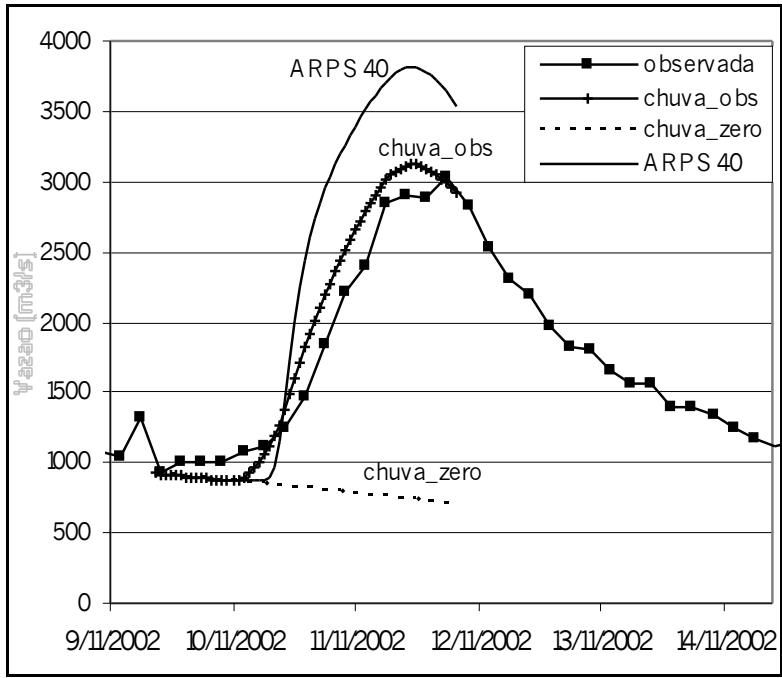

Figura 11 - Previsões de vazão realizadas para o evento de 9 a 12 de nov de 2002, iniciadas no dia 09/nov às 09:00 horas.

As figuras 11 até 15 apresentam os resultados das previsões. A figura 11 mostra a vazão observada e as vazões previstas no instante $T_{0}=09: 00$ horas do dia 09/nov/2002, pelos diferentes métodos: a vazão prevista considerando chuva nula a partir de $\mathrm{T}=0$; a vazão prevista com base na previsão de chuva do modelo ARPS de $40 \mathrm{~km}$ de resolução e a vazão prevista com base na chuva observada. Obviamente, 
a previsão baseada na chuva observada não pode ser utilizada operacionalmente. Entretanto, esta previsão é importante para a comparação com as previsões baseadas na previsão quantitativa de chuva. Se o número de postos pluviográficos na bacia fosse muito grande, e estes postos fossem bem distribuídos e apresentassem poucas falhas, poder-se-ia dizer que a previsão de vazão com base na chuva observada representa o limite superior de qualidade que pode ser obtido com a metodologia proposta. Em outras palavras, a previsão de vazão com base na chuva observada equivaleria a uma previsão de vazão baseada em uma previsão perfeita de chuva.

Observa-se, na figura 11, que a previsão de vazão considerando precipitação nula a partir do instante $\mathrm{T}_{0}=$ 09:00 horas do dia 09/nov indica uma contínua redução da vazão ao longo das 48 horas seguintes, aproximadamente. Por outro lado, a previsão de vazão baseada na previsão de chuva do modelo ARPS de $40 \mathrm{~km}$ indica a ocorrência de uma cheia, atingindo uma vazão superior a $3.700 \mathrm{~m}^{3} \mathrm{~s}^{-1}$ ao longo do dia 11/nov/2002.

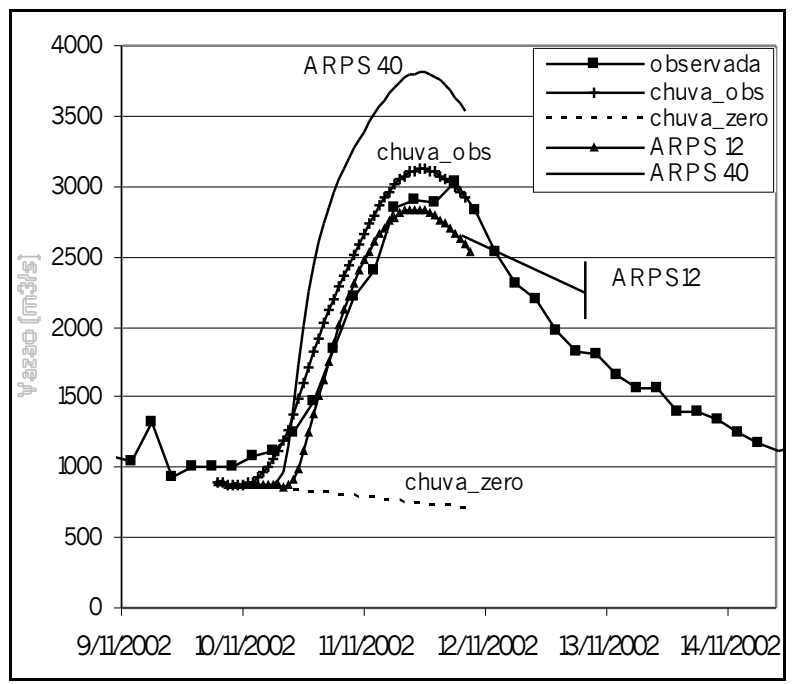

Figura 12 - Previsões de vazão realizadas para o evento de 9 a 12 de nov de 2002, iniciadas no dia 09/nov às 19:00 horas.

$\mathrm{Na}$ previsão do instante $\mathrm{T}_{0}=19: 00$ do dia 09/nov/2002, apresentada na figura 12, é acrescentada ainda a previsão de vazão baseada na previsão de chuva do modelo ARPS de $12 \mathrm{~km}$ de resolução. Esta previsão indica uma vazão de pico pouco inferior a $3.000 \mathrm{~m}^{3} \mathrm{~s}^{-1}$, com antecedência de, aproximadamente, 36 horas. A previsão baseada no modelo
ARPS de $12 \mathrm{~km}$ é muito boa, tanto com relação à vazão de pico, como ao tempo de pico. Já a previsão com base no modelo ARPS de $40 \mathrm{~km}$ é muito boa em relação ao tempo de pico, porém, superestima a vazão de pico em torno de $26 \%$.

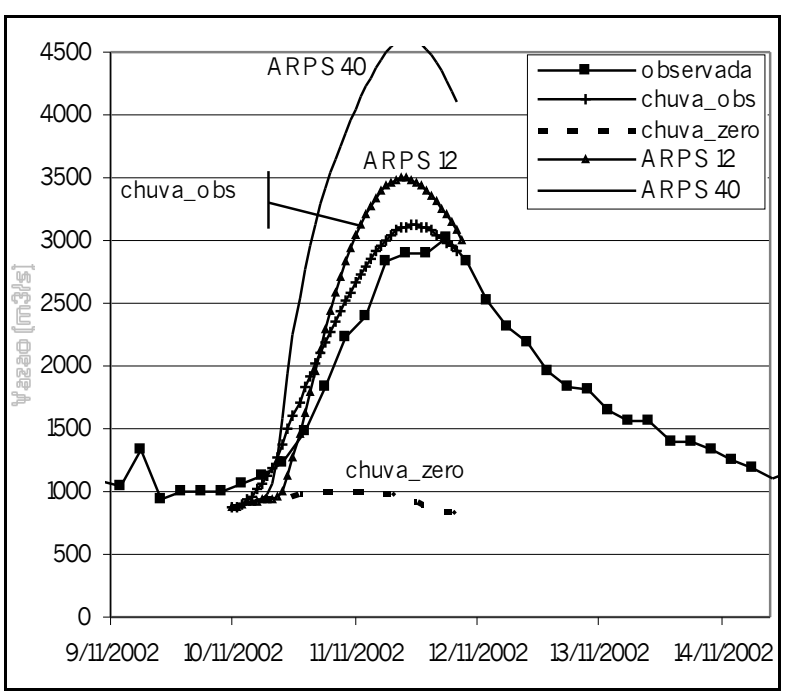

Figura 13 - Previsões de vazão realizadas para o evento de 9 a 12 de nov de 2002, iniciadas no dia 09/nov às 24:00 horas.

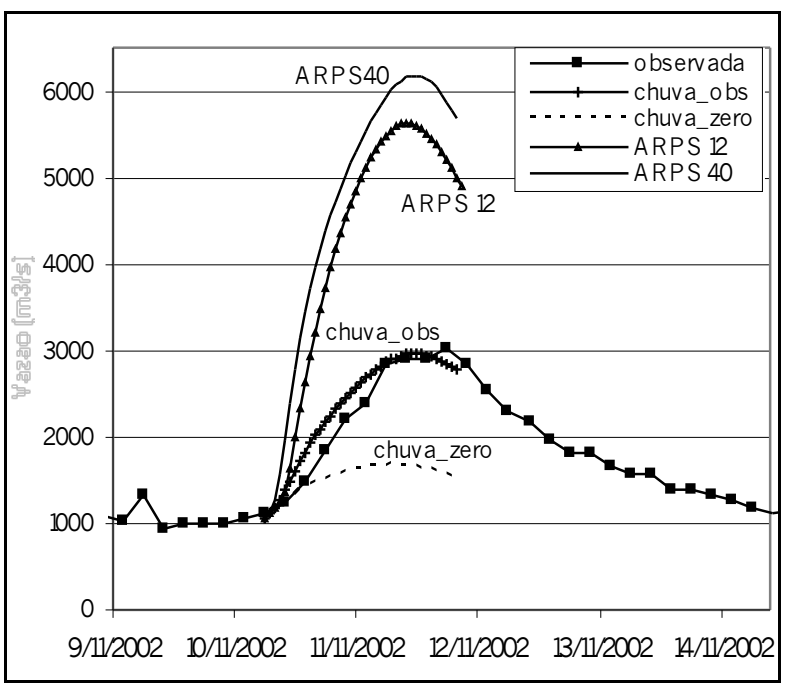

Figura 14 - Previsões de vazão realizadas para o evento de 9 a 12 de nov de 2002, iniciadas no dia 10/nov às 06:00 horas.

Na figura 13, que apresenta as previsões de vazão do instante $\mathrm{T}_{0}=24: 00$ horas do dia 
09/nov/2002, observa-se que o pico da cheia, previsto com base na previsão de chuva do modelo ARPS de $40 \mathrm{~km}$ passa para $4.500 \mathrm{~m}^{3} \mathrm{~s}^{-1}$, aproximadamente. Isto ocorre porque a chuva ocorrida e observada nos postos pluviométricos e pluviográficos até o instante $\mathrm{T}_{0}=24: 00$ horas do dia 09/nov/2002 é somada à precipitação prevista a partir deste momento, resultando em vazões maiores do que as previstas inicialmente. Ainda assim, as previsões de vazão baseadas na previsão quantitativa de chuva com o modelo ARPS são melhores do que a previsão de vazão baseada na hipótese de chuva nula a partir de $\mathrm{T}_{0}$, principalmente quando confrontadas às previsões originadas pelo modelo ARPS 12. Já na figura 14 , observa-se que as previsões realizadas no instante $\mathrm{T}_{0}=06: 00$ horas do dia 10/nov/2002 superestimam muito a cheia, indicando vazões de pico duas vezes superiores às observadas.

Finalmente na figura 15 observa-se que a previsão de vazão realizada em $\mathrm{T}_{0}=12: 00$ do dia 10/nov/2002, considerando precipitação zero a partir deste instante representa bem a subida do hidrograma e fornece uma boa estimativa do pico da cheia, que ocorre quase 24 horas depois, porém, a vazão é superestimada pelo ARPS 40.

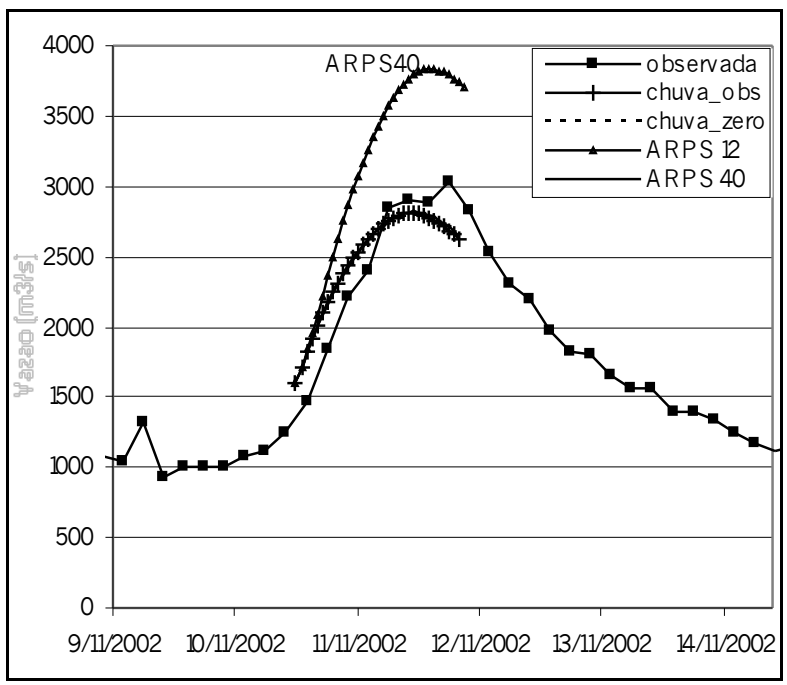

Figura 15 - Previsões de vazão realizadas para o evento de 9 a 12 de nov de 2002, iniciadas no dia 10/nov às 12:00 horas.

Neste evento observa-se um dos erros típicos da previsão de chuva (erro temporal). Comparando a precipitação acumulada em todo o evento, a chuva prevista pelo modelo ARPS, tanto de $40 \mathrm{~km}$ como de $12 \mathrm{~km}$, é muito próxima da chuva observada, e, por isso, as previsões de vazão realizadas antes do início da chuva observada (figura 11 - $\mathrm{T}_{0}=09: 00$ horas do dia 09/nov; e figura $12-\mathrm{T}_{0}=19: 00$ horas do dia 09/nov) apresentam resultados excelentes. Entretanto, as chuvas previstas apresentam diferenças na distribuição temporal em relação às chuvas observadas. A principal diferença é que as chuvas previstas ocorrem de forma concentrada, em algumas horas, enquanto as chuvas observadas são um pouco mais prolongadas, se iniciam antes, e são menos intensas. Em conseqüência, as previsões de vazão realizadas depois do início da chuva (figura 13 e 14) sobrepõe a chuva observada e prevista, resultando em picos de cheia muito superiores aos observados.

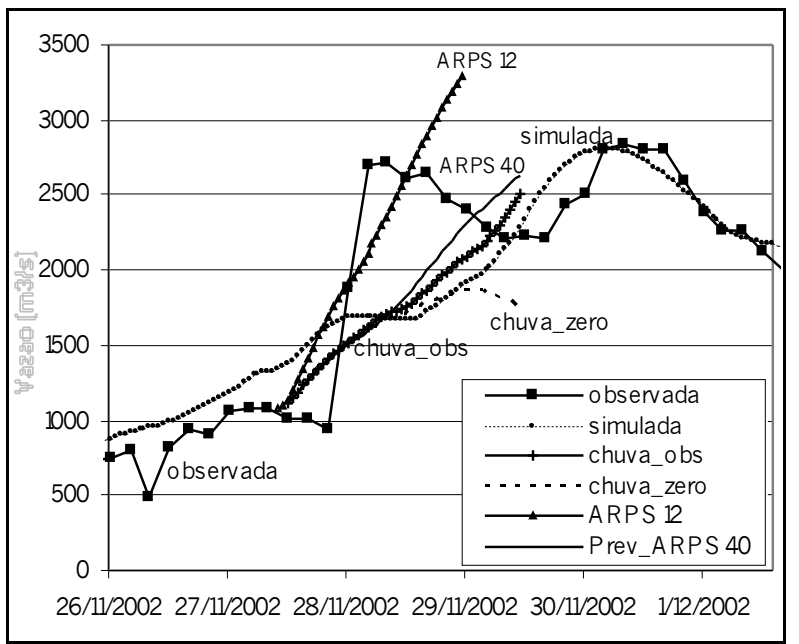

Figura 16 - Previsões de vazão realizadas para o evento de 25/nov a 02/dez de 2002 iniciadas no dia 27/nov às 21:00 h

Portanto, no caso do evento de 09 a 12 de novembro de 2002, em que a vazão afluente ao reservatório de Machadinho atingiu cerca de 3.000 $\mathrm{m}^{3} \mathrm{~s}^{-1}$, as previsões de vazão com base na previsão de chuva indicaram um aumento significativo das vazões, com antecedência de 48 horas, fornecendo, inclusive, uma boa estimativa da magnitude e do tempo de ocorrência do pico. Entretanto, a chuva prevista apresentou distribuição temporal diferente da observada e, em conseqüência, a metodologia de previsão, que inclui chuva observada e chuva prevista, resultou em uma forte superestimativa da vazão de pico para a antecedência próxima de 36 horas. Finalmente, para antecedência de 24 horas, as previ- 
sões das vazões de pico e dos tempos em que essas ocorreram, pelos métodos (ARPS $12 \mathrm{~km}$ e chuva zero), ficaram muito próximas do observado, porém, as vazões foram superestimadas pelo modelo ARPS 40 em torno de $25 \%$. Neste evento não foram utilizadas previsões do modelo ARPS de $4 \mathrm{~km}$ de resolução. Analisando as figuras 11 a 15, pode-se dizer que as previsões de vazão baseadas nas previsões do modelo ARPS de $12 \mathrm{~km}$ de resolução foram mais corretas do que as do modelo ARPS de $40 \mathrm{~km}$.

Também foram analisadas previsões realizadas para o período de 20 a 30 de novembro de 2002, em que ocorreu um evento cuja vazão de pico atingiu $2.800 \mathrm{~m}^{3} \mathrm{~s}^{-1}$ em Machadinho, com resultados semelhantes. A figura 16 apresenta a previsão realizada no dia 27/nov às 21:00 horas. Nesta figura também se apresenta a vazão simulada a qual difere da vazão previsão utilizando dados de chuva observada por: i) nesta em cada intervalo de tempo do modelo a vazão é atualizada e ii) as condições iniciais são diferentes.

É interessante observar, na figura 16 , que as previsões de vazão baseadas na previsão de chuva são melhores do que as previsões baseadas na chuva observada. Possivelmente a chuva ocorreu de forma bastante intensa sobre áreas da bacia mal monitoradas pela rede de pluviógrafos existente, ou então as vazões observadas, resultantes do balanço hídrico do reservatório de Machadinho, tenham erros associados. Esses erros prováveis podem ser observados também pela comparação entre a curva simulada e observada que apresenta diferenças consideráveis.

\section{CONCLUSÕES}

Neste trabalho descreve-se uma metodologia de previsão de vazão baseada na simulação da transformação chuva-vazão utilizando um modelo matemático que representa a bacia hidrográfica do rio Uruguai até Machadinho e um modelo regional de previsão quantitativa de chuva. Esta metodologia foi aplicada em três eventos isolados ocorridos em 2001 e 2002. Foram avaliados tempos de antecedência das previsões entre 1 e 48 horas, e os testes de previsão de vazão mostraram que a utilização de previsões de chuva do modelo ARPS permite antecipar a ocorrência de cheias mesmo em horizontes de 48 horas, melhorando significativamente as previsões de vazão em relação à hipótese de se considerar para o futuro a previsão de chuva nula a partir do tempo atual, especialmente para tempos de antecedência superiores ao tempo de concentração da bacia.

A comparação das previsões obtidas com as diferentes versões do modelo ARPS (04, 12 e 40 km) não mostrou vantagens evidentes em utilizar as previsões dos modelos de mais alta resolução, embora durante o evento mais importante de todo o período analisado, ocorrido entre setembro e outubro de 2001, as previsões sejam claramente melhores para os modelos de mais alta resolução. Os eventos de novembro de 2002 também são um pouco melhor previstos pelo modelo ARPS 12 do que pelo ARPS 40.

Também não ficou clara uma tendência das previsões de chuva em subestimar ou superestimar a precipitação na bacia, embora no evento de setembro e outubro de 2001 a chuva observada tenha sido superior à prevista por todas as versões do modelo ARPS.

A comparação dos resultados com as previsões de vazão baseadas na "previsão perfeita" de chuva (chuva observada) revelam que a metodologia de previsão de vazão pode se beneficiar muito de futuros incrementos da qualidade das previsões de chuva, especialmente para tempos de antecedência superiores a 12 horas.

\section{REFERÊNCIAS}

ANDERSON, R. J., (1993). A study of wind stress and heat flux over the open ocean by the inertial dissipation method. J. Phys. Oceanogr., vol. 23, pp. 2153-2161.

ANDREOLLI, I. (2003). Previsão de vazão em tempo real no rio Uruguai com base na previsão meteorológica. Dissertação de mestrado, IPH/UFRGS, Porto Alegre- RS.

BRASETH, A. M. (1986). Statistical interpotation by means of successive corrections. Tellus, vol. 38 A, pp. 439447.

BREWSTER, K. (1996). Application of a bratseth analysis scheme including doppler radar data. Preprints, 15th Conference on Weather Analysis and Forecasting. Amer. Meteor. Soc., Norfolk, VA, 92-95.

CASTILHO, A. S. \& OLIVEIRA, L. M. (2001). Previsão hidrológica de vazões para a cidade de Governador Valadares utilizando um modelo linear de propagação, in Anais, XIV Simpósio Brasileiro de Recursos Hídricos, ABRH: Aracaju, SE.

CHOU, M. D. (1990). Parameterization for the absorption of solar radiation by $\mathrm{O}_{2}$ and $\mathrm{CO}_{2}$ with application to climate studies. J. Climate, vol. 3, pp. 209-217.

CHOU, M. D. (1992:). A solar radiation model for climate studies. J. Atmos. Sci., Vol. 49, pp. 762-772. 
COLLIER, C. G., \& KRZYSZTOFOWICZ, R. (2000). Quantitative precipitation forecasting. Journal of Hydrologic Engineering, vol. 239, pp. 1-2.

COLLISCHONN, W., HAAS, R., ANDREOLLI, I. \& TUCCI, C. E. M. (2005).Forecasting River Uruguay flow using rainfall forecasts from a regional weather prediction model. Journal of Hydrology, vol 305,pp 87-98.

COLLISCHONN, W., TUCCI, C. E. M, , DIAS, P. L. S. \& CLARKE, R. T. (2003) Previsão sazonal de vazão na bacia do rio Uruguai 2: Previsão climáticahidrológica, Submetido à Revista Brasileira de Recursos Hidricos.

COLLISCHONN, W. (2001) Simulação hidrológica de grandes bacias, Tese de Doutorado, IPH/UFRGS, Porto Alegre - RS.

DAMRATH, U., DOMS, FRÜHWALD, G., HEISE, D., RICHTER, E., B., \& STEPPELER, J. (2000). Operational quantitative precipitation forecasting at the German Weather Service. Journal of Hydrologic Engineering, vol. 239, pp. 260-285.

HASS, J., MINE, R. M., FERNANDES, C. V. S. (2003). Feasibility of meteorological rainfal forecast to improve hydroplant reservoir inflows forecasts. World water congress, Madrid.

HASS, J., MINE, R. M. (2002). Avaliação das previsões meteorológicas quantitativas de precipitação geradas pelos modelos ETA (CPTEC) e MBAR (INMET). XII congresso brasileiro de meteorologia, Foz do lguaçu. A metodologia e a gestão de energia. Rio de Janeiro: SBMET, 2002. pp. 3601-3608.

HASS, J. (2002). Validação do uso da previsão meteorológica de chuva na previsão de afluências. Dissertação de mestrado, UFPR, Curitiba - PR.

HAAS, R., DOTTA, D. \& DECKER, I. C. (2003). Validação de um sistema de previsão quantitativa de chuva para 0 sul do Brasil. II CITENEL, Salvador, BA.

HOLLINGSWORTH, A. (2003). Improvements in the skill of numerical weather prediction with global models, Bulletin World Meteorological Organization, vol. 52, pp. 33-39.

JASPER, K., GURTZ, J. \& LANG, H. (2002). Advanced flood forecasting in Alpine watersheds by coupling meteorological observations and forecasts with a distributed hydrological model. Journal of Hydrologic Engineering, vol. 267, pp. 40-52.

KAIN, J. S., AND J. M. FRITSCH, (1993): Convective parameterization for mesoscale models: The Kain-Fritsch scheme, the representation of cumulus convection in numerical models. Meteor. Monogr. Amer. Meteor. Soc., pp. 165-170

KOUSSIS, A. D., LAGOUVARDOS, K., MAZI, K., KOTRONI, V., SITZMANN, D., LANG, J., ZAISS, H., BUZZI, A., \& MALGUZZI, P. (2003). Flood forecasts for urban basin with integrated hydro-meteorological model.
Journal of Hydrologic Engineering, vol. 7, pp. 1-11.

LETTENMAIER, D. P. \& WOOD, E. F. (1993). Hydrologic Forecasting, In: D.R. Maidment, Handbook of hydrology, New York, McGraw-Hill.

LIN, Y., R.D. FARLEY, AND H.D. ORVILLE, (1983): Bulk parameterization of the snow field in a cloud model. J. of Appl. Meteor., vol. 22, pp. 1065-1092.

MINE, M. R. M., (1998). Método Determinístico para Minimizar o Conflito entre Gerar Energia e Controlar Cheias, Tese de doutorado, IPH/UFRGS, Porto Alegre - RS.

NOILHAN, J., PLANTON, S., (1989). A simple parameterization of land surface processes for meteorological models. Mon. Wea. Rev. 117, pp. 536-549.

REFSGAARD, J. C. Validation and intercomparison of different updating procedures for real-time forecasting. Nordic Hydrology, v. 28, p. 65-84, 1997.

SMITH, K. T. \& AUSTIN, G. L. (2000). Nowcasting precipitation - a proposal for a way forward. Journal of Hydrology, vol. 239, pp. 34-45.

SUN, W. Y., AND CHANG, C. Z. (1985). Diffusion model for a convective layer. Part I: Numerical simulation of convective boundary layer. Journal of Applied Meteorology, vol. 25, No. 10, pp. 1445-1453.

TAO, W.-K., AND J. SIMPSON, (1993): Goddard cumulus ensemble model. Part I: Model description. Terres. Atmos. Ocean Sci., vol. 4, pp. 35-72.

TUCCI, C. E. M., COLLISCHONN, W., \& ANDREOLLI, I. (2003) Previsão de vazões de curto e médio prazo na operação de usinas hidrelétricas, IPH/UFRGS. Relatório Técnico, P\&D ANEEL.

TUCCI, C. E. M. (1998) Modelos hidrológicos, Porto Alegre: Editora da UFRGS, pp. 669.

WOOD, A.W., MAURER, E.P., KUMAR, A., \& D.P. LETTENMAIER (2002). Long range experimental hydrologic forecasting for the eastern U.S. Journal of Geophysical Research, vol. 36, pp. 70-86.

XUE, M., WANG, D.H., GAO, J. D., BREWSTER, K. \& DROEGEMEIE, K. K. (2001). The Advanced Regional Prediction System (ARPS)- A Multiscale Nonhydrostatic Atmospheric Simulation and Prediction Tool. Part II: Model Physics and Applications. Meteorology and Atmospheric Physics, vol. 76, pp. 143-165.

XUE, M., DROEGEMEIER, K. K. \& WONG, V. (2000). The Advanced Regional Prediction System (ARPS)- A Multi-scale Nonhydrostatic Atmospheric Simulation and Prediction Model. Part I: Model Dynamics and Verification. Meteorology and Atmospheric Physics, vol. 75, pp. 161-193.

YAPO, P. O., GUPTA, H. V. \& SOROOSHIAN, S. (1998) Multiobjective global optimization for hydrologic models. Journal of Hydrologic Engineering, vol. 204, pp. 8397.

YU, Z., LAKHTAKIA, M. N., YARNAL, B., WHITE, R. A., 
MILLER, D. A., FRAKES, B., BARRON, E. J., DUFFY C. \& SCHWARTZ, F. W. (1999). Simulating the river basin response to atmospheric forcing by linking a mesoscale meteorological model and hydrological model system. Journal of Hydrologic Engineering, vol. 218, pp. 72-91.

ZAMANILLO, E. (1987). Previsão em tempo real em uma hidrovia controlada por barragens, Dissertação de mestrado, IPH/UFRGS, Porto Alegre - RS.

\title{
Forecast Of Reservoir Inflow Using Quantitative Precipitation Forecasting
}

\begin{abstract}
Real-time streamflow forecasts are obtained using hydrologic models that calculate future flow. They can be used for flood warnings and for hydroelectric system operation. Flow forecasts can be based on channel-routing, rainfall-runoff transformation or on both techniques. This paper describes a forecasting methodology of inflows to a hydroelectric reservoir based on rainfall-runoff simulation by a distributed hydrologic model using observed rainfall and predicted rainfall from a regional numerical weather prediction model. The methodology was applied in the Uruguay river basin, down to the Machadinho reservoir which is located between the states of Rio Grande do Sul and Santa Catarina. We obtained forecasts for three flood events in 2001 and 2002. Results show that streamflow forecasts can benefit largely from quantitative precipitation forecasts.
\end{abstract}

Key-words: Real-time forecasting, hydrological forecasting, meteorological forecasting, hydrologic models. 